\title{
Implementasi Algoritma Turbo Boyer Moore untuk Pencarian Data pada Transaksi Keuangan Duta Phonecell Sawah Lebar
}

\author{
Gunawan $^{1}$, Kirman $^{2}$ \\ ${ }^{1,2}$ Dosen Tetap Program Studi Sitem Informasi Fakultas Teknik Universitas Muhammadiyah Bengkulu \\ Alamat (Jl. Bali Kota Bengkulu; e-mail: gunawan@umb.ac.id ${ }^{1}$, kirman@umb.ac.id²)
}

\begin{abstract}
A Small Medium Business is often abbreviated as (UKM in Indonesian), this is an important part of the economy growth in country and region. Duta Phonecell Sawah Lebar is one of the suppliers or credits traders. In conducting this business still use books for recording transactions system and a place to save the summary of data from data sources and collect data from various sources. Through this system can help to know or evaluate the business process that is being conducted. One of the Matching String Algorithms is the Boyer Moore Algorithm, through this a file wants to be executed; the file is not immediately allowed to be done. This study carried out at Duta Phonecell Sawah Lebar of Bengkulu City. The Turbo Boyer Moore Algorithm cannot be used in searching process because it is not proven to be used on objects and the page fields are too small and have not searched for texts in a long texts sequence. This application was successfully created, but did not implement the Turbo Boyer Moore Algorithm. The suggestion of this study tried to continue the application of Turbo Boyer Moore Algorithm in searching process on a long and accompanied by the Turbo Boyer Moore Algorithm that only searched for specific texts in all long texts data.

Keywords: UKM, Duta, Strings, Booyer More.
\end{abstract}

Intisari-Usaha Kecil Menengah atau sering disingkat UKM yang merupakan salah satu bagian penting dari perekonomian suatu negara maupun daerah, Duta phonecell sawah lebar merupakan salah satu suplier atau pedagang pulsa. Pada sistem yang sedang berjalan pencatatan transaksi masih menggunakan buku. tempat penyimpanan ringkasan data dari data sumber dan mengumpulkan data dari berbagai sumber agar dapat diperoleh pandangan yang lebih baik dari suatu proses bisnis. Salah satu algoritma string matching yang digunakan adalah algoritma boyer moore. Dimana algoritma pencocokan string boyer moore sebuah file ingin dieksekusi, maka file tersebut tidak langsung diizinkan untuk dijalankan, Penelitian dilaksanakan di Duta Phonecell yang beralamatkan Jln Sawah lebar Kota Bengkulu. Algoritma turbo boyer moore tidak dapat digunakan dalam proses pencarian karena tidak terbukti digunakan pada objek. Hal ini karena halaman field yang terlalu kecil dan belum mencari tesk pada suatu urutan tesk yang panjang. Aplikasi memang berhasil dibuat tatapi tidak menerapkan algoritma turbo boyer moore. Saran untuk penelitian ini adalah untuk mencoba melanjutkan penerapan algoritma turbo boyer moore pada proses pencarian di suatu tesk yang panjang dan banyak. Disertai juga algoritma turbo boyer moore hanya untuk mencari tesk tertentu yang berbeda pada seluruh data tesk yang panjang Kata Kunci : UKM, Duta, String, Booyer More

\section{PENDAHULUAN}

Usaha Kecil Menengah atau sering disingkat UKM yang merupakan salah satu bagian penting dari perekonomian suatu negara maupun daerah, begitu juga negara indonesia. UKM ini juga sangat membantu negara atau pemerintah dalam hal penciptaan lapangan kerja baru dan lewat UKM juga banyak tercipta unit kerja baru yang menggunakan tenaga baru yang dapat mendukung pendapatan rumah tangga. Untuk dapat menggunakan layanan telepon, sms dan internet melalui telepon genggam, telepon gengam harus memiliki pulsa. Semakin banyaknya pengguna telepon genggam semakin banyak pula yang membutuhkan pulsa. Terkait hal tersebut maka bermunculanlah para suplier atau pedagang pulsa dan salah satunya adalah duta phonecell sawah lebar.

Duta phonecell sawah lebar merupakan salah satu suplier atau pedagang pulsa. Pada sistem yang sedang berjalan pencatatan transaksi masih menggunakan buku. Hal ini menyebabkan pencarian laporan transaksi memerlukan waktu yang relatif lama karena harus melakukan rekapitulasi data seperti melihat buku catatan penjualan setiap hari untuk mengetahui laporan transaksi. Selain masalah pengolahan data yang cukup banyak, hampir 400 data transaksi penjualan dan media pemasaran masih sangat minim dalam pemasaran produk penjualan pada duta phonecell sawah lebar.

Sistem penyimpanan data yang berbasis cloud merupakan solusi permasalahan ini, tempat penyimpanan ringkasan data dari data sumber dan mengumpulkan data dari berbagai sumber agar dapat diperoleh pandangan yang lebih baik dari suatu proses 
bisnis. Pembuatan perangkat lunak yang mendukung akses informasi mengenai data transaksi dapat diakses melalui perangkat bergerak berbasis Android. Hasil dari pencarian sebuah String tergantung dari teknik atau cara pencocokan string yang digunakan, string matching merupakan proses pencocokan string untuk menemukan kesamaan antara teks dan pattern. Salah satu algoritma string matching yang digunakan adalah algoritma boyer moore. Dimana algoritma pencocokan string boyer moore sebuah file ingin dieksekusi, maka file tersebut tidak langsung diizinkan untuk dijalankan, namun akan dilakukan pengecekan terlebih dahulu. Kesimpulan yang diperoleh algoritma boyer moore lebih baik hal performansi karena tidak memerlukan permrosesan ekstra dan memungkinkan untuk mengingat potongan teks yang telah diperiksa sebelumnya.

\section{Tinjauan Pustaka}

\section{A. Implementasi}

Menurut Kamus Besar Bahasa Indonesia, implementasi adalah pelaksanaan dan penerapan, dimana kedua hal ini bermaksud untuk mencari bentuk tentang hal yang disepakati terlebih dahulu. Implementasi adalah proses untuk memastikan terlaksananya suatu kebijakan dan tercapainya kebijakan tersebut. Tujuan dari implementasi sebuah sistem ialah untuk menyelesaikan desain sistem yang telah disetujui, menguji serta mendokumentasikan program-program dan prosedur sistem yang diperlukan, memastikan bahwa personil yang terlibat dapat mengoperasikan sistem yang baru dan memastikan bahwa konversi sistem lama ke sistem baru dapat berjalan dengan baik dan benar[1].

\section{B. Aplikasi}

Aplikasi berasal dari kata application yang artinya penerapan, lamaran, penggunaan. Secara istilah aplikasi adalah: program siap pakai yang direka untuk melaksanakan suatu fungsi bagi pengguna atau aplikasi yang lain dan dapat digunakan oleh sasaran yang dituju[2].

\section{String Matching}

Algoritma string matching adalah sebuah algoritma yang digunakan dalam pencocokkan suatu pola kata tertentu terhadap suatu kalimat atau teks panjang. Algoritma string matching sendiri dapat dilakukan dengan beberapa cara tertentu, antara lain cara Brute Force dan cara Knuth- Morris-Pratt (KMP)[3].

Pengertian string menurut Dictionary of Algorithms and Data Structures, National Institute of Standards and Technology (NIST) adalah susunan dari karakter-karakter (angka, alfabet atau karakter yang lain) dan biasanya direpresentasikan sebagai struktur data array. String dapat berupa kata, frase, atau kalimat.

Pencocokan string merupakan bagian penting dari sebuah proses pencarian string (string searching) dalam sebuah dokumen. Hasil dari pencarian sebuah string dalam dokumen tergantung dari teknik atau cara pencocokan string yang digunakan. Pencocokan string (string matching) menurut Dictionary of Algorithms and Data Structures, National Institute of Standards and Technology (NIST), diartikan sebagai sebuah permasalahan untuk menemukan pola susunan karakter string di dalam string lain atau bagian dari isi teks.

Pencocokan string (string matching) secara garis besar dapat dibedakan menjadi dua yaitu :

1. Exact string matching, merupakan pencocokan string secara tepat dengan susunan karakter dalam string yang dicocokkan memiliki jumlah maupun urutan karakter dalam string yang sama. Contoh : kata step akan menunjukkan kecocokan hanya dengan kata step.

2. Inexact string matching atau Fuzzy string matching, merupakan pencocokan string secara samar, maksudnya pencocokan string dimana string yang dicocokkan memiliki kemiripan dimana keduanya memiliki susunan karakter yang berbeda (mungkin jumlah atau urutannya) tetapi string-string tersebut memiliki kemiripan baik kemiripan tekstual/penulisan (approximate string matching) atau kemiripan ucapan (phonetic string matching). 
Inexact string matching dibagi menjadi dua yaitu :

a. Pencocokan string berdasarkan kemiripan penulisan (approximate string matching) merupakan pencocokan string dengan dasar kemiripan dari segi penulisannya (jumlah karakter, susunan karakter dalam dokumen). Tingkat kemiripan ditentukan dengan jauh tidaknya beda penulisan dua buah string yang dibandingkan tersebut dan nilai tingkat kemiripan ini ditentukan oleh pemrogram (programmer). Contoh : c mpuler dengan compiler, memiliki jumlah karakter yang sama tetapi ada dua karakter yang berbeda. Jika perbedaan dua karakter ini dapat ditoleransi sebagai sebuah kesalahan penulisan maka dua string tersebut dikatakan cocok.

b. Pencocokan string berdasarkan kemiripan ucapan (phonetic string matching) merupakan pencocokan string dengan dasar kemiripan dari segi pengucapannya meskipun ada perbedaan penulisan dua string yang dibandingkan tersebut. Contoh step dengan steb dari tulisan berbeda tetapi dalam pengucapannya mirip sehingga dua string tersebut dianggap cocok. Contoh yang lain adalah step, dengan steppe, sttep, stepp, stepe [4].

\section{Algoritma Turbo Booyer Moore}

Algoritma Boyer-moore menggunakan konsep Boyer-moore sebagai ide awalnya. Tidak diperlukan pemrosesan tambahan lagi. Proses awalan pada pattern sama dengan proses awalan pada pattern yang dilakukan dengan Boyer-moore Dua keunggulan dari algoritma ini, yaitu :

1. Teknik ini memungkinkan untuk melompati faktor dari teks tersebut.

2. Teknik ini mengijinkan sebuah pergeseran turbo.

Perpindahan yang dilakukan ketika proses pencarian string akan berbeda dengan proses yang dilakukan pada algoritma Boyer moore. Perpindahan ini disebut dengan perpindahan turbo. Perpindahan turbo ini hanya dapat dilakukan jika pada saat melakukan perbandingan pada saat tersebut, panjang dari karakter yang sama antara pattern dan teks lebih besar dari panjang dari karakter sama yang telah disimpan sebelumnya di variabel factor pengingat. Akibatnya, proses pencarian akan menjadi lebih singkat.

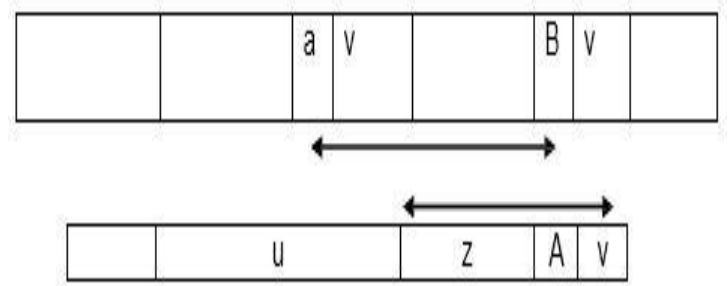

Gambar 1. Pergeseran Turbo
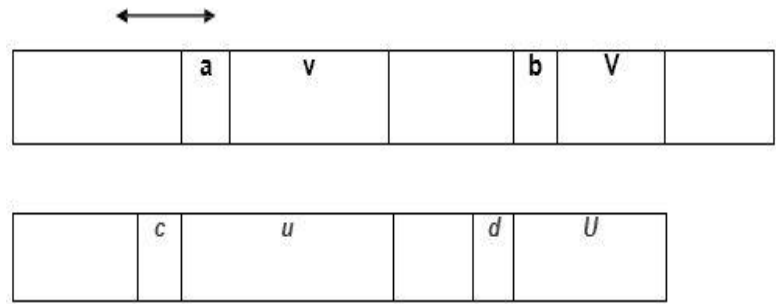

Gambar 2. $c \neq d$, Disejajarkan Pada Karakter

Adapun Prinsip kerja dari algoritma Turbo

Boyer-moore adalah sebagai berikut :

1. Algoritma Turbo Boyer-moore mulai mencocokkan pattern pada awal teks.

2. Dari kanan ke kiri, algoritma ini akan mencocokkan karakter per karakter pattern dengan karakter pada teks yang bersesuaian sampai salah satu kondisi berikut dipenuhi :

a. Di pattern dan di teks yang dibandingkan tidak cocok (missmatch).

b. Semua karakter di pattern cocok. Algoritma akan memberitahukan penemuan di posisi ini.

c. Algoritma kemudian menggeser pattern dengan memaksimalkan nilai penggeseran good-suffix dan

d. penggeseran bad-character, Lalu mengulangi langkah 2 sampai pattern berada di ujung teks. 
Adapun solusi penyelesaian algoritma Turbo Boyer-moore adalah Untuk fase pencarian dalam algoritma Turbo Boyer Moore, proses yang dilakukan hampir sama dengan fase pencarian pada Algoritma Boyer Moore. Yang membedakan adalah adanya variabel yang berfungsi untuk menampung nilai pergeseran apabila pada putaran sebelumnya nilai yang diambil untuk pergeseran berasal dari tabel good suffix shift.

Nilai ini nantinya akan digunakan sebagai nilai yang mungkin digunakan untuk pergeseran pattern. Fase inisialisasi pada algoritma ini sama dengan fase inisialisasi pada algoritma Boyer Moore, yaitu mempunyai kompleksitas waktu dan ruang sebesar $\mathrm{O}$ $(n+\sigma)$ dengan $\sigma$ adalah besar ruang alfabet. Sedangkan pada fase pencocokan, algoritma ini mempunyai kompleksitas waktu sebesar $\mathrm{O}(\mathrm{m})$ dengan jumlah pencocokan karakter pada algoritma ini adalah $2 \mathrm{~m}[5]$.

\section{Metodologi Penelitian}

Adapun Metode penelitian yang penulis gunakan adalah Rapid Aplication Development (RAD) merupakanstrategi pengembangansistem yang menekankan kecepatan pengembangan melalui keterlibatan pengguna yang ekstensif dalm konstruksi, cepat, berulang dan bertambah serangkaian prototype bekerja sebuah sistem yang pada akhirnya berkembang didalam sistem final. Berikut ini adalah gambaran kerangka pemikiran dari Rapid Aplication Development (RAD).

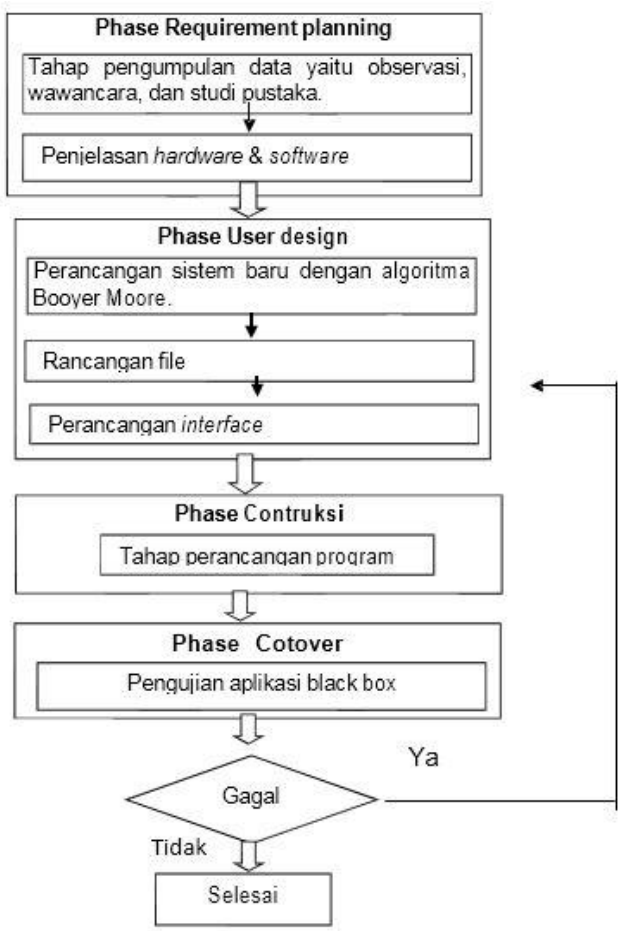

Gambar 3. Metode RAD

Untuk perancangan sistem dalam diagram alir data terdapat 2 atribut, yaitu admin dan suplier. Kemudian memiliki 3 tabel yaitu tabel transaksi, tabel kategori, dan tabel harga. Adapun diagram alir data dalam penelitian ini dapat dilihat pada Gambar 4 dibawah ini

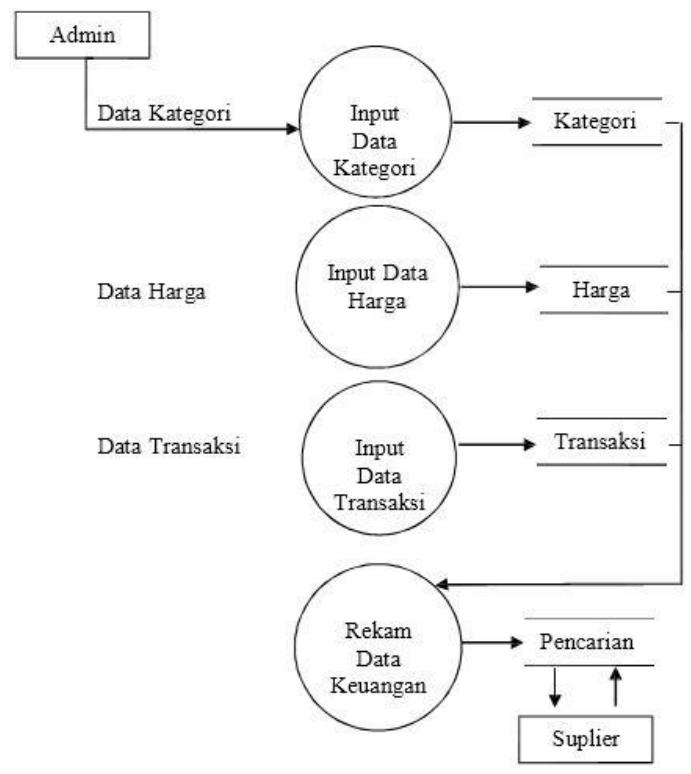

Gambar 4. Diagram Alir Data 


\section{HASIL DAN PEMBAHASAN}

\section{A. Hasil dan Pembahasan Sistem}

Hasil penelitian implementasi algoritma turbo boyer moore untuk pencarian data pada transaksi keuangan Duta Phonecell Sawah Lebar, adalah sebagai berikut :

1. Menerapkan algoritma turbo boyer moore pada pencarian transaksi penjualan di Duta Phonecell Sawah Lebar berdasarkan nama pelanggan.

2. DaPat menerapkan sistem server dan penyimpanan data secara online, sehingga data dapat di akses pada 2 aplikasi yaitu berbasis website dan berbasis android. Urutan proses dari aplikasi transaksi keuangan duta phonecell Sawah Lebar adalah sebagai berikut :

\section{a. Tampilan SplashScreen}

Tampilan splashscren merupakan tampilan awal dalam aplikasi ini, terdapat informasi judul penelitian dan progressbar saat akan menampilkan data. Adapun tampilan splashscreen dapat dilihat pada gambar 5.

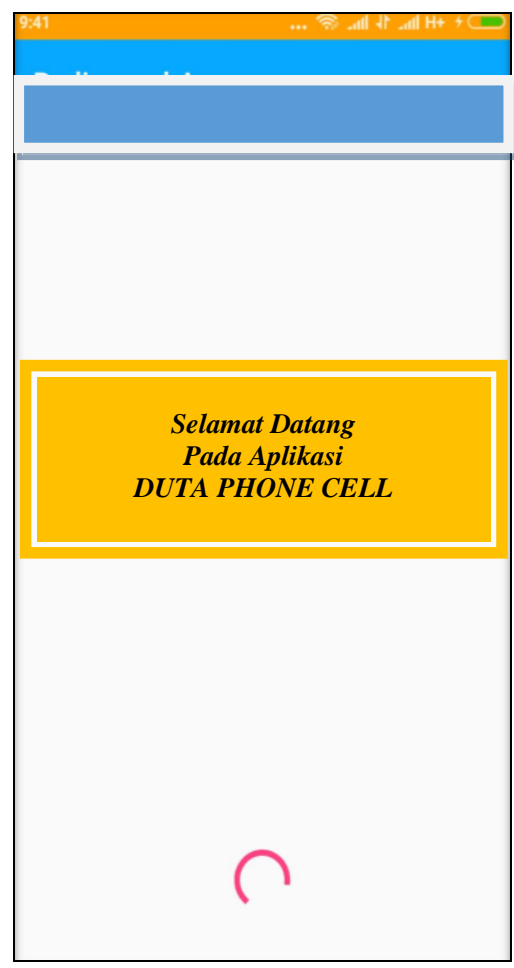

Gambar 5. Splash Screen

\section{b. Tampilan Login}

Tampilan login merupakan tampilan sistem keamanan dalam aplikasi ini, adapun tampilan login dapat dilihat pada Gambar 6

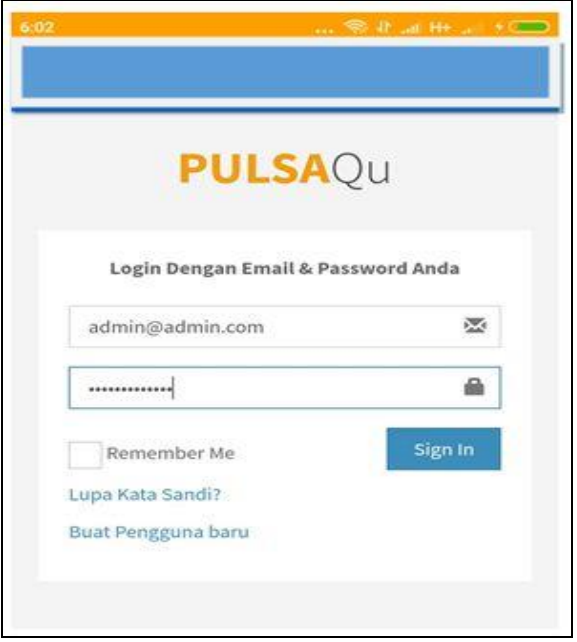

Gambar 6. Halaman Login Aplikasi

\section{c. Tampilan Home}

Tampilan home merupakan tampilan awal dalam aplikasi ini, terdapat 4 menu utama yaitu transaksi, laporan transaksi, info, dan keluar. Adapun tampilan home dapat dilihat pada Gambar 7.

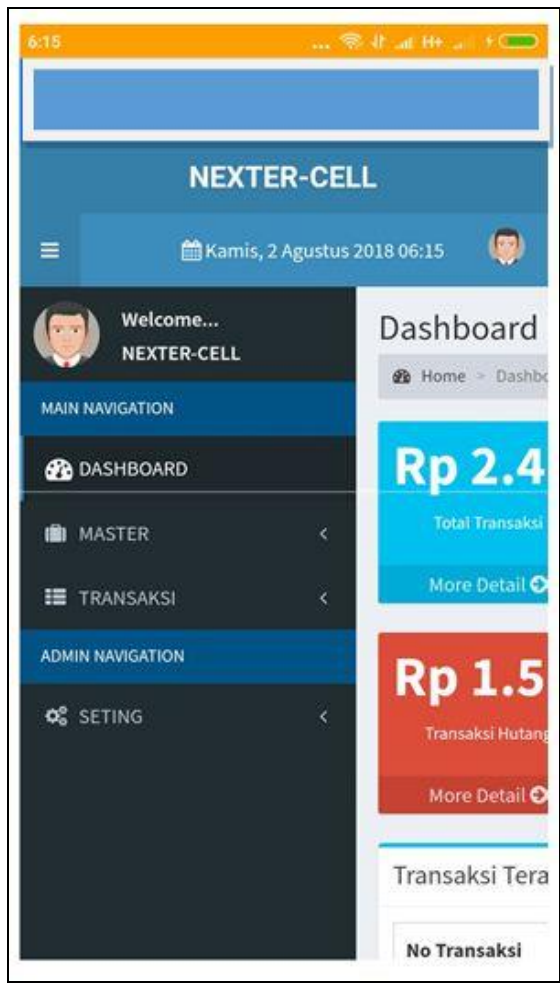

Gambar 7. Tampilan Home 


\section{d. Tampilan Transaksi}

Tampilan transaksi merupakan tampilan input data dalam melakukan transaksi penjualan, adapun tampilan transaksi dapat dilihat pada gambar 8

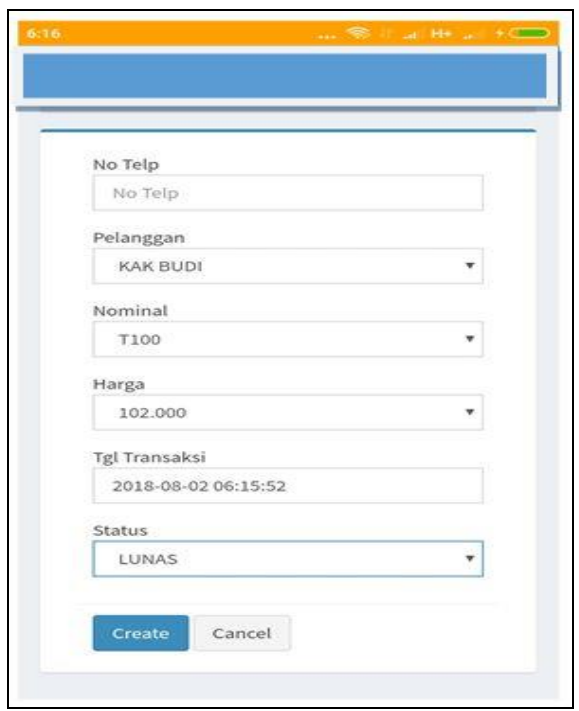

Gambar 8. Menu Transaksi

e. Tampilan Laporan Transaksi

Tampilan laporan transaksi merupakan tampilan laporan dalam melakukan transaksi penjualan, adapun tampilan laporan transaksi dapat dilihat pada gambar 9 .

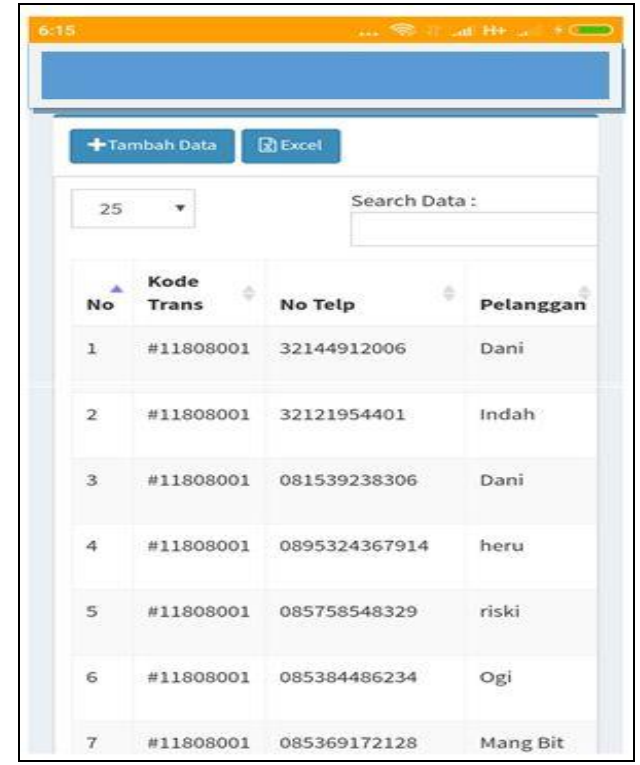

Gambar 9. Laporan Transaksi

\section{B. Pembahasan}

Dalam pembahasan ini aplikasi algoritma turbo boyer moore digunakan untuk mencari transaksi keuangan duta phonecell Sawah Lebar, tampilan dapat dilihat pada gambar 10. Algoritma turbo boyer moore seperti yang dijelaskan pada halaman terdahulu diterapkan pada proses mencari data. Kode program untuk memproses awal dimulai dari tesk yang diinput pengguna pada objek form text box seperti yang tampak pada gambar 10 .

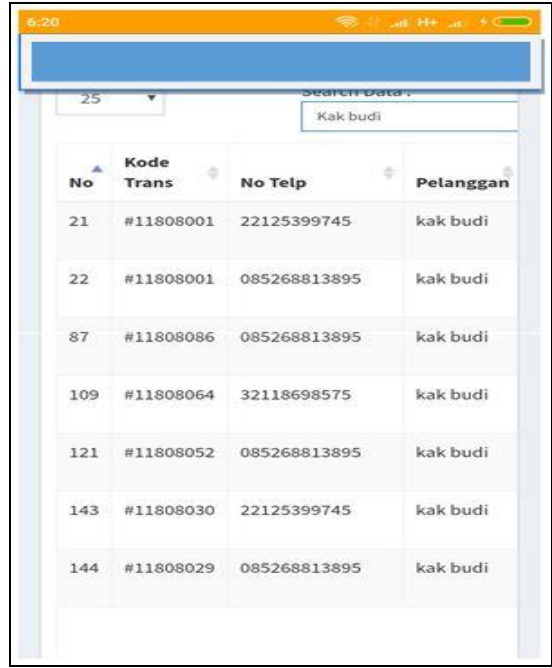

Gambar 10. Menu Pencarian Data

Kode tersebut tersimpan pada file tb_transaksi_form. Pattern tesk awal yang berasal dari objek form merupakan langka awal pada pencocokan awal algoritma turbo boyer moore. Kode lengkap pengambil text pattern tersebut seperti pada berikut ini

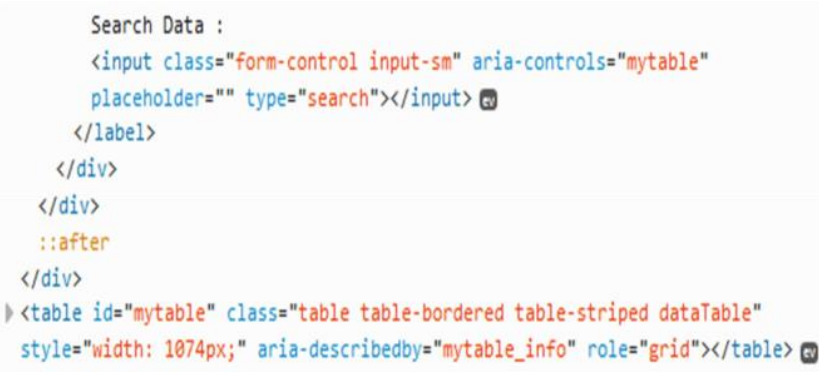

Selanjutnya proses algoritma ini akan mencocokan karakter per karakter pattern dengan karakter pada tesk yang terdapat pada hasil query sql antara tabel transaksi dengan tabel pelanggan. Pada proses pencarian selanjutnya tidak ada pergeseran pattern tesk yang diambil. Selanjutnya pencarian yang keluar adalah pencarian hanya dari proses query pada fungsi ajax yang ada bukan di algoritma turbo boyer moore. 
$<$ section class='content-header'>

$<$ h1 $>$

TRANSAKSI

<small>Daftar Semua Transaksi</small>

$</$ h1 $>$

$<$ ol class='breadcrumb'>

$<$ ii $><$ a href='\#' $><$ i class='fa fa-

suitcase' $></$ i $>$ Transaksi $</$ a $></$ i $>$

$<$ i class='active' $>$ Daftar Semu Transaksi $</ \mid \mathrm{i}>$

$</$ ol $>$

$</$ section $>$

$<$ script $\mathrm{src}=$ " $<$ ?php echo

base_url('assets/js/plugins/datatables/jquery-

1.11.3.min.js');

? $>$ " $><$ script $>$

$<$ script $>$

$\$($ document).ready(function()\{

$\$$.fn.dataTable.ext.errMode = 'throw';

\$('\#mytable').dataTable( \{ "Processing": true,

"ServerSide": true, "iDisplayLength": 25, "oLanguage": \{

"sSearch": "Search Data : ", "sZeroRecords": "Data Masih

Kosong", "sEmptyTable": "No data available in table"

\} ,

"ajax": "<?php echo base_url('transaksi/view_data');?>",

"columns": [

\{ "mData": "no" \},

\{ "mData": "kode_transaksi" \},

\{ "mData": "no_telp" \},

\{ "mData": "nama_pelanggan" \},

\{ "mData": "nominal" \},

\{ "mData": "harga" \},

\{ "mData": "tgl_transaksi" \},

\{ "mData": "status" \},

\{ "mData": "detail" \},

\{ "mData": "edit" \}, ],

"footerCallback": function (row, data, start, end,

display) \{

summation

var api = this.api(), data;

var intVal = function (i) \{

return typeof $\mathrm{i}===$ 'string' ?

i.replace $\left(/,{ }^{*} \mid \backslash \mathrm{D} / \mathrm{g}\right.$, " $) * 1$ :

typeof $\mathrm{i}===$ 'number' ?

i : $0 ;\}$;

// Total over all pages

total $=$ api

.column(5)

data()

.reduce(function $(a, b)\{$

return intVal(a) + intVal(b);

\}$, 0)$;

// Total over this page

pageTotal $=$ api

.column(5, \{page: 'current'\})

.data()

.reduce(function $(a, b)\{$

return intVal(a) + intVal(b);

\}, 0);

\section{Penutup}

\section{A. Kesimpulan}

Dari hasil aplikasi Implementasi algoritma turbo boyer moore untuk aplikasi transaksi keuangan duta phonecell Sawah Lebar, dapat ditarik kesimpulan Bahwa Algoritma turbo boyer moore tidak dapat digunakan dalam proses pencarian karena tidak terbukti digunakan pada objek. Hal ini karena halaman field yang terlalu kecil dan belum mencari tesk pada suatu urutan tesk yang panjang. Aplikasi memang berhasil dibuat tatapi tidak menerapkan algoritma turbo boyer moore.

\section{B. Saran}

Saran untuk penelitian ini adalah untuk mencoba melanjutkan penerapan algoritma turbo boyer moore pada proses pencarian di suatu tesk yang panjang dan banyak. Disertai juga algoritma turbo boyer moore hanya untuk mencari tesk tertentu yang berbeda pada seluruh data tesk yang panjang.

\section{Daftar Pustaka}

[1] Wijaya, A., \& Gunawan, G. (2018). Implementasi Algoritma Round Robin Pada Sistem Penjadwalan Mata Kuliah (Studi Kasus: Universitas Muhammadiyah Bengkulu). Jurnal Informatika Upgris, 4(1)

[2] Arif, S. N., Wanda, A. P., \& Masudi, A. (2013). Aplikasi Administrasi Perpustakaan Berbasis Web SMK Swasta Brigjend Katamso Medan. Jurnal SAINTIKOM Vol, 12(1).

[3] Rossaria, M., Susilo, B., \& Ernawati, E. (2015). Implementasi Algoritma Pencocok

[4] an String Knuth Morris-Pratt dalam Aplikasi Pencarian Dokumen Digital Berbasis Android. Rekursif: Jurnal Informatika, 3(2).

[5] Syaroni, M., \& Munir, R. (2005). Pencocokan String Berdasarkan Kemiripan Ucapan (Phonetic String Matching) dalam Bahasa Inggris. In Seminar Nasional Aplikasi Teknologi Informasi (SNATI).

[6] ANDROID, B. M. B., \& KHOLIFAH, E. N. APLIKASI BIOLOGI ELEKTRIK MENGGUNAKAN ALGORITMA. 